\title{
Psychosocial Functioning of Adolescents with Idiopathic Short Stature or Persistent Short Stature Born Small for Gestational Age during Three Years of Combined Growth Hormone and Gonadotropin-Releasing Hormone Agonist Treatment
}

\author{
Hanneke Visser-van Balen ${ }^{a, b}$ Rinie Geenen ${ }^{c}$ Mirjam Moerbeek ${ }^{d}$ \\ Rutger Stroop ${ }^{\mathrm{a}}$ Gerdine A. Kamp $^{\mathrm{e}}$ Jaap Huisman ${ }^{\mathrm{f}}$ Jan M. Wit ${ }^{\mathrm{g}}$ \\ Gerben Sinnema ${ }^{a}$ \\ Departments of a Pediatric Psychology, University Medical Center Utrecht, Wilhelmina Children's Hospital, \\ ${ }^{\mathrm{b}}$ Developmental Psychology, ${ }^{\mathrm{c}}$ Health Psychology, and ${ }^{\mathrm{d}}$ Methodology and Statistics, Utrecht University, Utrecht; \\ ePediatrics, Gooi-Noord Hospital, Blaricum; ${ }^{f}$ Medical Psychology, VU University Medical Center, Amsterdam, \\ and ${ }^{\mathrm{g}}$ Pediatrics, Leiden University Medical Center, Leiden, The Netherlands
}

\section{Key Words}

Idiopathic short stature $\cdot$ Small for gestational age .

Psychological adaptation - Growth hormone •

Gonadotropin-releasing hormone agonist

\begin{abstract}
Aim: To examine psychosocial functioning of medically referred adolescents with idiopathic short stature (ISS) or persistent short stature born small for gestational age (SGA) during 3 years of combined growth hormone (GH) and gonadotropin-releasing hormone agonist ( $\mathrm{GnRHa}$ ) treatment. Methods: Thirty-eight adolescents participated in a controlled trial with $\mathrm{GH} / \mathrm{GnRHa}$ treatment or no intervention. Each year the adolescents and their parents completed questionnaires and structured interviews. Multilevel analysis was used to analyze data. Results: The adolescents of the treatment group showed a worse outcome than the adolescents of the control group on 3 of 16 variables: perceived competence of scholastic $(p<$ $0.01)$ and athletic ability $(p<0.05)$ and trait anxiety $(p<$ $0.05)$. Adolescents in both the treatment and control
\end{abstract}

groups perceived improved current height $(p<0.001)$ and self-appraisal of physical appearance $(p<0.05)$. The parents did not report changes in their children during treatment. Conclusion: The observation of some adverse psychological consequences as experienced by the adolescents indicates that it is useful to monitor psychosocial functioning during a combined $\mathrm{GH} / \mathrm{GnRHa}$ treatment in adolescents with ISS or SGA. It is uncertain whether the hypothesized positive effects of the expected gain in final height by adulthood can sufficiently counterbalance possible short-term negative effects.

Copyright (c) 2005 S. Karger AG, Basel

\section{Introduction}

The ultimate effects of growth hormone $(\mathrm{GH})$ treatment in short, healthy children - with no apparent organic pathology underlying the short stature (idiopathic short stature, ISS) [1] - are still uncertain. Short-term results show considerable gain in height velocity [2], whereas the effect on final height appears limited for regular

\section{KARGER}

Fax +41613061234 E-Mail karger@karger.ch www.karger.com

\section{(C) 2005 S. Karger AG, Basel}

0301-0163/05/0642-0077\$22.00/0

Accessible online at:

www.karger.com/hre
Hanneke Visser-van Balen, MSc

Utrecht University, Department of Developmental Psychology

PO Box 80140

NL-3508 TC Utrecht (The Netherlands)

Tel. +3130253 9055, Fax +3130253 4718, E-Mail J.Visser-vanbalen@fss.uu.nl 
substitution dosages [3,4] and approximately $7 \mathrm{~cm}$ for higher dosages [5-7]. Children born small for gestational age (SGA) with persistent short stature have a birth length of more than two standard deviations below the mean for gestational age [8]. They show an adequate response to GH treatment in the first years and there is probably a substantial benefit of GH on final height [9].

In adolescents with ISS, it is assumed that GH treatment has only a limited effect when puberty has already started, because a promoting effect on growth velocity may coincide with an acceleration of pubertal development and bone maturation [10]. As a consequence, little gain in final height may result. In an effort to enhance the effect of GH and increase final height, addition of a gonadotropin-releasing hormone agonist ( $\mathrm{GnRHa}$ ), a substance that delays pubertal development, has been used. Early uncontrolled studies of a combined treatment of $\mathrm{GH}$ and GnRHa showed a gain in final height prediction between -0.5 and $10 \mathrm{~cm} \mathrm{[11-17].} \mathrm{We} \mathrm{reported} \mathrm{the} \mathrm{3-year}$ results of a randomized controlled trial in early pubertal adolescents with ISS or SGA [18]. GnRHa was effective in suppressing pubertal development and skeletal maturation, whereas the addition of GH preserved growth velocity during treatment. This resulted in a substantial gain in predicted adult height of about $8 \mathrm{~cm}$ for girls and $10 \mathrm{~cm}$ for boys, without demonstrable physical side effects. However, long-term results in terms of final adult height are pending.

The use of combined GH and GnRHa treatment has led to discussions with respect to the possible benefits of enhancing growth versus the possible adverse effects of treatment, especially the psychosocial consequences of delaying pubertal development in short, but otherwise healthy adolescents [19]. The benefits of the treatment, in terms of height gain, will not become apparent until after treatment, when extra growth takes place through the still open epiphyses. During the 3 years of treatment, growth in the treated adolescents is similar to that in the untreated adolescents, although puberty is arrested. A different timing of pubertal progression relative to peers has been associated with feelings of being different which may lead to anxiety and problems with respect to self-esteem, identity, and body image [20-23]. These possible adverse effects of treatment may add to the negative consequences of short stature. Furthermore, daily GH and monthly GnRHa injections represent an intensive and invasive treatment. The ultimate question is whether the longterm height benefits are large enough to compensate for possible psychosocial costs of delayed puberty and other potential adverse effects of the treatment.
In one study, the psychosocial effects of a combined $\mathrm{GH}$ and GnRHa treatment were examined in adopted children with early puberty [24]. Psychological evaluation did not reveal psychosocial problems in adopted children before treatment nor a change of emotional or behavioral adjustment during treatment. Self-concept did not change, but perceived acceptance by peers increased. It was concluded that delaying puberty by administering GnRHa had no negative effects on psychosocial well-being.

Our study examined 38 medically referred short adolescents who agreed to participate in an experimental trial of a combined treatment of GH and GnRHa, and compared the results with short adolescents who received no intervention. Participants had a height standard deviation score (SDS) below -2 , or between -1 and -2 with a predicted adult height SDS below -2, all without apparent underlying pathology. Twenty-six participants had a normal birth weight and length and were classified as ISS, while 12 were born SGA. Both ISS and SGA have been associated with problems in behavior, social functioning, school competence, and attention [25-27], while SGA has also been associated with lowered intelligence and mild neurological dysfunctions $[25,26,28]$. To examine the effect of combined GH and GnRHa treatment on the psychosocial functioning of medically referred adolescents with ISS or SGA, we evaluated the frequency of height-related psychosocial stressors, self-perceptions of height, and psychosocial functioning during 3 years of treatment.

\section{Methods}

Study Sample and Procedures

Four Dutch hospitals participated in this multicenter study: the University Medical Center Utrecht - Wilhelmina Children's Hospital, the VU University Medical Center Amsterdam, the Sophia Children's Hospital Rotterdam, and the Catharina Hospital Eindhoven [18]. The first 40 referred adolescents who fulfilled the inclusion criteria and agreed to participate after having been informed about the study participated in our randomized controlled trial with $\mathrm{GH} / \mathrm{GnRHa}$ treatment or no intervention.

The inclusion criteria for participation in the study were as follows: being in early puberty as documented by Tanner breast stage 2 or 3 for girls and Tanner genital stage 2 or 3 for boys; a measured height SDS for the same age and sex of less than -2.0 , or a height SDS between -1.0 and -2.0 with a predicted adult height of more than -2.0 SDS; a chronological age and bone age of less than 12 years for girls and 13 years for boys; a documented $\mathrm{GH}$ response of $>20 \mathrm{mU} / \mathrm{l}(>10 \mu \mathrm{g} / \mathrm{l})$ after a standard provocation test and/or during a sleep test; a ratio of sitting height/subischial leg height between the 3rd and 97th percentiles, and normal blood tests and urinalysis [18]. 
Table 1. Anthropometric and demographic characteristics at baseline of girls and boys with idiopathic short stature (ISS) or born small for gestational age (SGA)

\begin{tabular}{|c|c|c|c|c|c|c|c|c|}
\hline & \multicolumn{2}{|l|}{ ISS } & & & \multicolumn{2}{|l|}{ SGA } & & \\
\hline & \multicolumn{2}{|c|}{ girls $(n=17)$} & \multicolumn{2}{|c|}{ boys $(n=9)$} & \multicolumn{2}{|c|}{ girls $(n=8)$} & \multicolumn{2}{|c|}{ boys $(n=4)$} \\
\hline & mean & SD & mean & SD & mean & SD & mean & SD \\
\hline Age & 11.3 & 0.7 & 11.9 & 0.8 & 11.3 & 1.0 & 11.8 & 0.5 \\
\hline Height, cm & 135.25 & 5.06 & 136.65 & 9.10 & 133.17 & 3.61 & 132.37 & 2.10 \\
\hline Height SDS & -2.01 & 0.56 & -2.66 & 0.57 & -2.29 & 0.41 & -2.76 & 0.39 \\
\hline Predicted adult height, $\mathrm{cm}^{*}$ & 151.8 & 1.0 & 168.4 & 2.6 & 154.3 & 3.3 & 165.9 & 3.2 \\
\hline Predicted adult height SDS* & -2.65 & 0.16 & -2.02 & 0.39 & -2.24 & 0.53 & -2.40 & 0.48 \\
\hline & $\mathrm{n}$ & $\%$ & $\mathrm{n}$ & $\%$ & $\mathrm{n}$ & $\%$ & $\mathrm{n}$ & $\%$ \\
\hline $\begin{array}{l}\text { Parents married or living together } \\
\text { Education of parents }\end{array}$ & 12 & 70.6 & 6 & 66.7 & 8 & 100 & 3 & 75 \\
\hline Primary & 4 & 23.5 & 0 & 0 & 1 & 12.5 & 0 & 0 \\
\hline Secondary & 6 & 35.3 & 4 & 44.4 & 2 & 25.0 & 3 & 75.0 \\
\hline Tertiary & 7 & 41.2 & 5 & 55.6 & 5 & 62.5 & 1 & 25.0 \\
\hline
\end{tabular}

* Girls with ISS $n=16$, boys with ISS $n=8$. SDS $=$ Standard deviation score.

The randomization procedure was performed separately for ISS and SGA. After randomization, 20 adolescents were assigned to the combination therapy, while the other 20 adolescents did not receive treatment. Immediately after randomization, two participants (one from the treatment group and one from the control group) decided to end their participation. The study sample consisted of 38 early pubertal adolescents ( 25 girls, 13 boys), aged from 11 to 13 years (mean age 11.5 years) at the start of the study. Most participants (17 girls, 9 boys) had a normal birth size and were classified as ISS Twelve adolescents ( 8 girls, 4 boys) were known to have had a birth length of more than $2 \mathrm{SD}$ below the mean for gestational age and were classified as SGA (table 1). There were 9 adolescents with a measured height SDS between -1.0 and -2.0 and a predicted adult height SDS of less than -2.0 . The most likely reason for the girls substantially outnumbering the boys is that the combination of short stature and early puberty is more common in girls than boys.

For 3 years the adolescents in the treatment group were given GH daily by subcutaneous injection 4 IU $(1.33 \mathrm{mg})$ per square meter body surface (Genotropin, Pharmacia, Sweden; now Pfizer, New York, N.Y., USA) and a depot preparation of $3.75 \mathrm{mg}$ GnRHa (Decapeptyl-CR, Ferring, Sweden) every 4 weeks administered intramuscularly. The adolescents in the control group were followed yearly to document their growth and pubertal development. Because of ethical considerations, we did not use placebo injections for the control group. Further details on growth parameters have previously been reported [18].

Before treatment, and 1,2 and 3 years after beginning the treatment, the adolescents and the parents of all participants in both groups completed questionnaires to assess the psychosocial functioning of the adolescents. The parents were also interviewed by a psychologist. Before treatment, the adolescents and their parents were examined in the interval between randomization and starting treatment. This interval was chosen for ethical reasons to avoid the suggestion that the answers of the parents or adolescents might affect group assignment.

Not all adolescents and parents participated at all assessments. In the treatment group, assessments were missing for 2 adolescents at the third assessment, and for an additional 8 adolescents at the final assessment. In the control group, 2 adolescents dropped out after the first assessment, and an additional 4 adolescents did so after the second assessment. Final assessments were missing for 5 more adolescents. In both treatment and control group there were incidental missing values, because adolescents or parents failed to fill out all questions. The adolescents who dropped out did not differ from the others with respect to diagnosis, gender, intelligence, marital status of the parents, parental education, or the baseline scores of height and psychological outcome variables. Participant attrition was attributable to limited motivation to complete the questionnaires.

The medical ethics committees at the four participating centers approved the study. The parents of all children provided written informed consent before participation.

\section{Psychological Measures}

Parental Reports. The parents (mostly mothers) were interviewed in order to learn what height-related psychosocial stressors (being teased or juvenilized; yes/no) their children encountered [29]. Parents were also asked about their worries for their child's future, whether they considered that the prospects of their child were equal to that of persons of normal height in the labor market and finding a spouse (yes, doubtful, no).

The parents completed the Child Behavior Check List (CBCL), which measures emotional and behavioral problems of children 
and adolescents [30]. The CBCL consists of the following eight syndrome areas (the so-called narrow-band scales): withdrawn behavior, somatic complaints, anxious/depressed behavior, social problems, thought problems, attention problems, delinquent behavior, and aggressive behavior. The scores of selected subscales are subsumed under the broad-band internalizing (i.e. withdrawn and anxious/depressed) and externalizing (i.e. aggressive and delinquent) scales. A total problem score is also generated.

Parental Reports and Adolescents'Self-Reports. The Silhouette Apperception Technique (SAT) has been shown to be a valid and useful instrument for assessing perceptions of the current and future heights of adolescents [24, 29, 31, 32]. This instrument was completed by both adolescents and their parents. Drawings depicting different heights, corresponding proportionally with the heights of the $3 \mathrm{rd}, 25 \mathrm{th}, 50 \mathrm{th}, 75 \mathrm{th}$ and 97 th percentiles, were presented and the adolescents and parents had to identify the drawings that they thought best fit the youth's current and adult height.

Adolescents' Self-Reports. The adolescents completed questionnaires regarding perceived competence, psychological distress, and personality characteristics.

Perceived competence was assessed using the Dutch version of the Self Perception Profile for Children (CBSK) and for Adolescents (CBSA). The CBSK consists of six perceived competence subscales: scholastic competence, social acceptance, athletic competence, physical appearance, behavior and conscience, and global selfworth [33]. Higher scores (on a four-point scale) reflect more positive self-perceptions. The CBSA consists of these six scales plus the scales of friendship and romantic love. In this longitudinal study we only used the six scales that the CBSK and the CBSA have in common [34].

Anxiety symptoms were assessed using the Dutch version of the State-Trait Anxiety Inventory for Children (ZBV-K), with the subscales of trait anxiety and state anxiety [35]. Trait anxiety is a stable proneness to anxiety, and state anxiety is an emotional state that depends on personality and the situation. Higher scores (on a fourpoint scale) reflect higher anxiety. The KDVK (short depression questionnaire for children) was used to assess depressive mood in the participants [36]. Personality characteristics of the participants were investigated using the Dutch Personality Questionnaire-Junior (NPV-J), with five subscales: inadequacy, perseverance, social inadequacy, recalcitrance, and dominance [37]. The higher the score, the more a certain characteristic is present.

\section{Data Analyses}

To analyze the correlated repeated measurements we used multilevel analysis [38]. Multilevel refers to multiple levels of nesting. Our study had two levels of nesting: repeated measures across years (level one) were nested within participants (level two).

The data were analyzed as follows. Outcome was predicted from treatment condition (coded 0 and 1 for the control and treatment group, respectively), time (which varied between 0 and 3 years), their interaction, and gender (coded 0 and 1 for boys and girls, respectively). Thus, for continuous outcomes we had the following multilevel model for measurement $i$ within adolescent $j$ :

$$
\begin{aligned}
\text { outcome }_{i j}= & \beta_{0}+\beta_{1} \text { treatment }_{j}+\beta_{2} \text { time }_{i j} \\
& +\beta_{3} \text { treatment }_{j} * \text { time }_{i j}+\beta_{4} \text { gender }_{j}+u_{j}+e_{i j} .
\end{aligned}
$$

The random effects $u_{j}$ and $e_{i j}$ account for inter- and intra-participant variability, respectively. Treatment and gender only vary between participants, and are indexed $j$ in the model, while time varies both between and within adolescents and is indexed $i j$ in the model. The intercept $\beta_{0}$ is the mean psychosocial adjustment for boys in the control group at baseline. The coefficient $\beta_{4}$ is the difference in the mean adjustment of boys and girls. An effect of the treatment is demonstrated in a different course of the outcome variable across the time of the treatment. The treatment by time interaction, treatment $*$ time, reflects whether the course of the outcome variable across the 3 years is different for the treatment and control group. If $\beta_{3}$ was not significantly different from zero, the interaction term was removed from the model and the model was refit using the remaining terms. In that case, $\beta_{1}$ is the difference in mean outcome between adolescents in the treatment and the control group, and $\beta_{2}$ is the yearly change in mean outcome. The statistical model did not control for the potential influence of demographic and diagnostic variables, because the small sample size prohibited the addition of more variables. Continuous, ordinal, and nominal data were analyzed by the computer programs MIXREG [39], MIXOR [40], and MIXNO [41], respectively. A type I error rate of $\alpha=0.05$ was used.

For significant differences between the treatment and control groups, we report the effect size as defined by Cohen [42]. Effect sizes express the difference between groups in standard deviation units. Effects sizes of $0.20,0.50$ and 0.80 standard deviation are considered small, moderate, and large, respectively.

Scores for the Self Perception Profile for Children/Adolescents, the State-Trait Anxiety Inventory for Children, the Dutch Personality Questionnaire-Junior, and the Child Behavior Check List are reported as standard deviation scores (SDS). The mean score of the appropriate age and sex group for the normative sample was subtracted from the participant's score after which these differences were divided by the standard deviation of the normative sample. Like the SDS score for height, this score expresses the difference from norms in standard deviation units.

From a statistical standpoint, the current sample size is small. For this reason, multilevel analysis was chosen because it accommodates missing values obviating the need to eliminate all data from a particular case. To assure that any differences observed over time were not attributable to selection factors associated with attrition, we separately examined the results of the adolescents who participated at all four measurements.

\section{Results}

\section{Baseline}

According to $28 \%$ of the parents their child was teased by peers because of short stature (15\% of the boys, 35\% of the girls), and $14 \%$ of parents reported that their child was juvenilized by peers (23\% of boys, $9 \%$ of girls). Regarding the effects of short stature on future expectations, $44.5 \%$ of the parents expected their child to have a lower prospect in the labor market as an adult (39\% of boys, $48 \%$ of girls) and 39\% expected their child to have a lower prospect of finding a spouse $(77 \%$ of the boys and $17 \%$ of the girls). This difference between boys and girls was significant $(\mathrm{p}<0.01)$. 
Table 2. Parental reports of height-related psychosocial stressors of adolescents in the treatment and control groups at baseline and after 1,2 and 3 years of treatment

\begin{tabular}{|c|c|c|c|c|c|c|c|c|c|c|c|c|c|c|c|c|}
\hline & \multicolumn{4}{|c|}{ Baseline } & \multicolumn{4}{|c|}{1 year } & \multicolumn{4}{|c|}{2 years } & \multicolumn{4}{|c|}{3 years } \\
\hline & \multicolumn{2}{|c|}{$\begin{array}{l}\text { treatment } \\
(\mathrm{n}=18)\end{array}$} & \multicolumn{2}{|c|}{$\begin{array}{l}\text { control } \\
(\mathrm{n}=18)\end{array}$} & \multicolumn{2}{|c|}{$\begin{array}{l}\text { treatment } \\
(\mathrm{n}=18)\end{array}$} & \multicolumn{2}{|c|}{$\begin{array}{l}\text { control } \\
(\mathrm{n}=16)\end{array}$} & \multicolumn{2}{|c|}{$\begin{array}{l}\text { treatment } \\
(\mathrm{n}=14)\end{array}$} & \multicolumn{2}{|c|}{$\begin{array}{l}\text { control } \\
(\mathrm{n}=11)\end{array}$} & \multicolumn{2}{|c|}{$\begin{array}{l}\text { treatment } \\
(\mathrm{n}=8)\end{array}$} & \multicolumn{2}{|c|}{$\begin{array}{l}\text { control } \\
(\mathrm{n}=6)\end{array}$} \\
\hline & $\mathrm{n}$ & $\%$ & $\mathrm{n}$ & $\%$ & $\mathrm{n}$ & $\%$ & $\mathrm{n}$ & $\%$ & $\mathrm{n}$ & $\%$ & $\mathrm{n}$ & $\%$ & $\mathrm{n}$ & $\%$ & $\mathrm{n}$ & $\%$ \\
\hline Adolescents that are teased & 6 & 33.3 & 4 & 22.2 & 3 & 16.7 & 4 & 25.0 & 1 & 7.1 & 3 & 27.3 & 2 & 25.0 & 0 & 0 \\
\hline Adolescents that are juvenilized & 4 & 22.2 & 1 & 5.6 & 2 & 11.1 & 0 & 0 & 0 & 0 & 0 & 0 & 0 & 0 & 1 & 16.7 \\
\hline \multicolumn{17}{|l|}{ Equal prospects on labor market? } \\
\hline Yes & 11 & 61.1 & 9 & 50.0 & 10 & 66.7 & 7 & 50.0 & 7 & 70.0 & 4 & 40.0 & 4 & 66.7 & 2 & 33.3 \\
\hline No & 6 & 33.3 & 5 & 27.8 & 2 & 13.3 & 4 & 28.6 & 3 & 30.0 & 2 & 20.0 & 1 & 16.7 & 2 & 33.3 \\
\hline Doubt & 1 & 5.6 & 4 & 22.2 & 3 & 20.0 & 3 & 21.4 & 0 & 0 & 4 & 40.0 & 1 & 16.7 & 2 & 33.3 \\
\hline \multicolumn{17}{|l|}{ Equal chance to find a partner? } \\
\hline Yes & 11 & 61.1 & 11 & 61.1 & 10 & 66.7 & 8 & 57.1 & 8 & 80.0 & 7 & 70.0 & 4 & 66.7 & 3 & 50.0 \\
\hline No & 5 & 27.8 & 5 & 27.8 & 4 & 26.7 & 4 & 28.6 & 1 & 10.0 & 2 & 20.0 & 1 & 16.7 & 2 & 33.3 \\
\hline Doubt & 2 & 11.1 & 2 & 11.1 & 1 & 6.7 & 2 & 14.3 & 1 & 10.0 & 1 & 10.0 & 1 & 16.7 & 1 & 16.7 \\
\hline
\end{tabular}

Parental ratings of behavioral problems on the $\mathrm{CBCL}$ were significantly higher for the short adolescents (treatment and control groups combined), compared with the Dutch population norms, on the narrow-band scales anxious/depressed behavior $(\mathrm{p}<0.05)$, social problems $(\mathrm{p}<$ $0.01)$, and attention problems $(\mathrm{p}<0.05)$ and on the broadband internalizing behavior $(\mathrm{p}<0.05)$ and total behavior problems $(p<0.05)$ scales. The effect sizes for these differences ranged from 0.50 to 0.73 , which are considered moderate in size.

Perceived competence and psychological distress did not generally differentiate the short stature participants at baseline from normative samples. Perceptions of social acceptance were even higher than in the instruments' normative sample $(\mathrm{p}<0.05)$. With respect to personality characteristics, participants with ISS or SGA described themselves as being more persistent (quiet, conscientious, and diligent) relative to norms $(\mathrm{p}<0.05)$.

None of the psychosocial variables showed statistically significant differences between the treatment and control group. Analyses of variance were performed to examine whether at baseline the participants' stature differed among children for whom parents did and did not perceive height-related psychosocial stressors. No significant effects were observed. Furthermore, none of the psychosocial variables differentiated adolescents with ISS from those with SGA. Intelligence scores (corrected total WISC$\mathrm{Rn}$ scores) ranged from 66 to 128 in the two groups, with a mean score of 99.8. Six adolescents (three ISS, three SGA) had an intelligence lower than 80 . The intelligence did not differ significantly between adolescents with ISS and those with SGA. Further details of the baseline status have been described elsewhere [43].

\section{Height-Related Psychosocial Stressors}

Reports of the parents about their child being teased and juvenilized did not differ for the two treatment conditions, did not change during the time of the treatment, and did not show a different course across time for the treatment and control groups (treatment by time interaction). These statistics are not shown in the tables, but the percentages of psychosocial stressors at each time point are (table 2).

Parents' expectations for their child's prospects to find a spouse or job as compared with peers of normal stature did not differ between treatment conditions, did not change over time, and did not show a different course over time for the treatment and control groups (table 2). A higher percentage of parents of girls than boys expected their child to have a normal probability of finding a spouse $(p=0.016)$. No significant gender effects were observed for parents' expectations of their child having equal prospects on the labor market.

\section{Parental Reports}

Table 3 provides the results of the assessments of the parents. To assist the reader to interpret this table, the results of perception of current height are explained in detail. The statistical parameters $\beta_{1}$ to $\beta_{4}$ refer to the equation in the data analysis section. Perception of cur- 
Table 3. Predictors (SEs) of outcomes of parental reports

\begin{tabular}{|c|c|c|c|c|c|}
\hline Scale & $\begin{array}{l}\text { Intercept } \\
\left(\beta_{0}\right)\end{array}$ & $\begin{array}{l}\text { Treatment } \\
\text { condition } \\
\left(\beta_{1}\right)\end{array}$ & $\begin{array}{l}\text { Time } \\
\left(\beta_{2}\right)\end{array}$ & $\begin{array}{l}\text { Treatment by } \\
\text { time inter- } \\
\text { action }\left(\beta_{3}\right)\end{array}$ & $\begin{array}{l}\text { Gender } \\
\left(\beta_{4}\right)\end{array}$ \\
\hline Perception current height & $1.37(0.20)$ & $-0.05(0.20)$ & $0.20(0.06)^{* * *}$ & n.f. & $0.01(0.21)$ \\
\hline Perception future height & $2.35(0.30)$ & $1.00(0.30)^{* *}$ & $-0.06(0.06)$ & n.f. & $-0.55(0.31)$ \\
\hline Total behavior & $0.49(0.34)$ & $0.09(0.35)$ & $-0.10(0.07)$ & n.f. & $-0.07(0.36)$ \\
\hline Internalizing behavior & $0.51(0.33)$ & $-0.10(0.33)$ & $-0.17(0.11)$ & n.f. & $0.05(0.34)$ \\
\hline Externalizing behavior & $0.27(0.30)$ & $0.08(0.31)$ & $-0.02(0.07)$ & n.f. & $-0.07(0.32)$ \\
\hline Withdrawn behavior & $0.14(0.28)$ & $-0.31(0.28)$ & $-0.06(0.06)$ & n.f. & $0.40(0.30)$ \\
\hline Somatic complaints & $0.63(0.36)$ & $0.49(0.37)$ & $-0.05(0.08)$ & n.f. & $-0.76(0.38)$ \\
\hline Anxious/depressed behavior & $0.43(0.31)$ & $-0.08(0.28)$ & $-0.20(0.11)$ & n.f. & $0.19(0.29)$ \\
\hline Social problems & $0.57(0.42)$ & $0.20(0.43)$ & $-0.09(0.09)$ & n.f. & $0.15(0.45)$ \\
\hline Thought problems & $-0.02(0.26)$ & $0.09(0.26)$ & $-0.07(0.07)$ & n.f & $0.31(0.27)$ \\
\hline Attention problems & $0.67(0.34)$ & $0.21(0.35)$ & $-0.11(0.07)$ & n.f. & $-0.30(0.36)$ \\
\hline Delinquent behavior & $0.07(0.34)$ & $0.32(0.35)$ & $-0.09(0.07)$ & n.f. & $0.07(0.36)$ \\
\hline Aggressive behavior & $0.35(0.29)$ & $0.00(0.30)$ & $-0.01(0.07)$ & n.f. & $-0.19(0.31)$ \\
\hline
\end{tabular}

$* \mathrm{p}<0.05 ;{ }^{* *} \mathrm{p}<0.01 ; * * * \mathrm{p}<0.001$. The significance of the intercept is ignored. Non-significant treatment by time interactions were removed from the multilevel model. n.f. $=$ Not fitted.

Table 4. Predictors (SEs) of outcomes of adolescents' self-reports

\begin{tabular}{lrrrrr}
\hline Scale & \multicolumn{1}{l}{$\begin{array}{l}\text { Intercept } \\
\left(\beta_{0}\right)\end{array}$} & $\begin{array}{l}\text { Treatment } \\
\text { condition } \\
\left(\beta_{1}\right)\end{array}$ & $\begin{array}{l}\text { Time } \\
\left(\beta_{2}\right)\end{array}$ & $\begin{array}{l}\text { Treatment by } \\
\text { time inter- } \\
\text { action }\left(\beta_{3}\right)\end{array}$ & \multicolumn{1}{c}{$\begin{array}{l}\text { Gender } \\
\left(\beta_{4}\right)\end{array}$} \\
\hline Perception current height & $1.58(0.22)$ & $-0.11(0.22)$ & $0.24(0.06)^{* * *}$ & \multicolumn{1}{l}{ n.f. } & $0.27(0.23)$ \\
Perception future height & $3.26(0.27)$ & $0.48(0.26)$ & $-0.01(0.07)$ & \multicolumn{1}{c}{ n.f. } \\
Scholastic competence & $-0.31(0.31)$ & $0.49(0.34)$ & $0.30(0.09)^{* * *}$ & $-0.35(0.12)^{* *}$ & $-0.47(0.28)$ \\
Social acceptance & $0.41(0.27)$ & $0.25(0.26)$ & $0.03(0.08)$ & n.f. & $-0.32(0.33)$ \\
Athletic competence & $-0.20(0.31)$ & $0.60(0.34)$ & $0.26(0.11)^{*}$ & $-0.40(0.15)^{*}$ & $0.06(0.31)$ \\
Physical appearance & $-0.03(0.28)$ & $0.05(0.29)$ & $0.16(0.07)^{*}$ & n.f. & $-0.35(0.30)$ \\
Behavior and conscience & $0.50(0.34)$ & $0.01(0.33)$ & $0.09(0.10)$ & n.f. & $-0.42(0.35)$ \\
Global self-worth & $-0.51(0.26)$ & $0.32(0.26)$ & $-0.03(0.08)$ & n.f. & $0.42(0.27)$ \\
Trait anxiety & $-0.03(0.28)$ & $-0.10(0.31)$ & $-0.22(0.11)^{*}$ & $0.29(0.14)^{*}$ & $-0.22(0.28)$ \\
State anxiety & $0.37(0.23)$ & $-0.17(0.22)$ & $-0.02(0.07)$ & n.f. & $-0.45(0.23)$ \\
Depressive mood & $0.99(0.30)$ & $-0.14(0.26)$ & $-0.03(0.11)$ & n.f. & $0.29(0.28)$ \\
Inadequacy & $-0.13(0.25)$ & $0.02(0.25)$ & $-0.04(0.05)$ & n.f. & $0.04(0.26)$ \\
Perseverance & $0.31(0.31)$ & $0.23(0.31)$ & $-0.02(0.07)$ & n.f. & $-0.20(0.33)$ \\
Social inadequacy & $-0.19(0.24)$ & $0.11(0.24)$ & $-0.07(0.06)$ & n.f. & $0.23(0.25)$ \\
Recalcitrance & $0.00(0.25)$ & $0.05(0.25)$ & $-0.10(0.06)$ & n.f. & $-0.08(0.27)$ \\
Dominance & $0.30(0.31)$ & $-0.24(0.30)$ & $0.01(0.07)$ & n.f. & $0.20(0.32)$ \\
& & & & &
\end{tabular}

$* \mathrm{p}<0.05 ; * * \mathrm{p}<0.01 ; * * * \mathrm{p}<0.001$. The significance of the intercept is ignored. Non-significant treatment by time interactions were removed from the multilevel model. n.f. $=$ Not fitted.

rent height was scored 1, 2, 3, 4, and 5 for the 3rd, 25th, 50th, 75th, and 97th percentiles, respectively. The perception of current height at baseline was $\beta_{0}=1.37$ (somewhere between the 3rd and 25th percentile) for boys in the control group. The mean perception of current height was $\beta_{1}=-0.05$, in other words, 0.05 lower for adolescents in the treatment group than in the control group; this difference was not statistically significant. The mean percep- 
Fig. 1. Scholastic competence, athletic competence, and trait anxiety scores of the treatment and control groups at baseline and 1, 2 , and 3 years after the start of the intervention. The scores are deviations from the mean of the norm group in SD units.
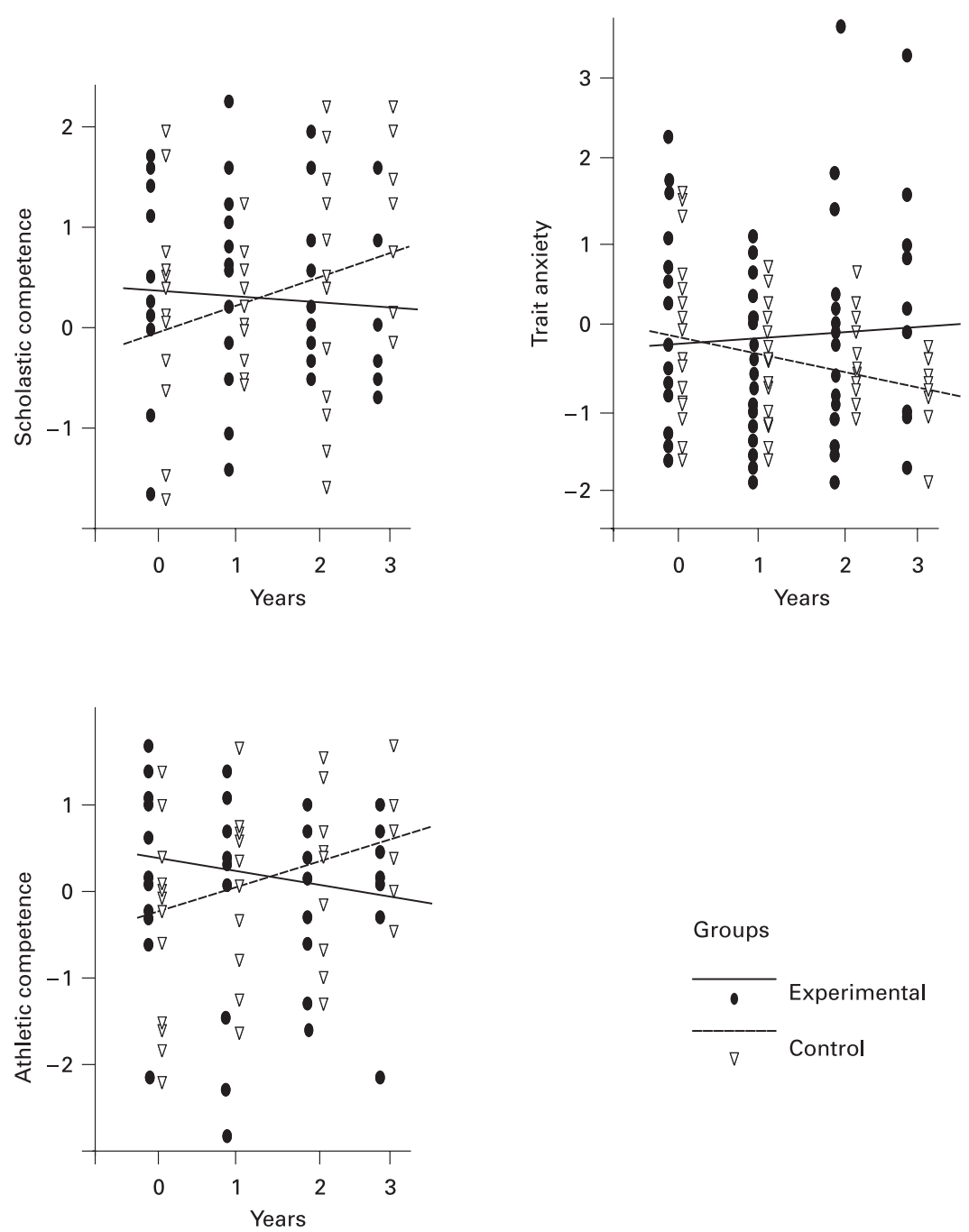

Groups

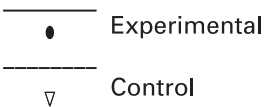

tion of height increased with $\beta_{2}=0.20$ each year (time effect: $p<0.001)$. The change of perception of height across the 3 years was not different for the treatment and the control groups: $\beta_{3}$ was not fitted (nf), because the treatment by time interaction was not significant. Finally, the perception of current height did not differ between girls and boys. A significant positive value of $\beta_{4}$ would have indicated that girls perceived themselves as being taller than boys.

The effects of treatment, time, the treatment by time interaction effect, and gender on the three broad-band factors and the eight narrow-band scales of the CBCL were not significant (table 3 ).

\section{Adolescents' Self-Reports}

Table 4 summarizes the results of the assessments of the adolescents.

Perception of current height was found to significantly increase with time, for both the treatment and control groups (time effect: $p<0.001$ ).

Self-perceptions of scholastic competence in the treatment group decreased over time, while that of the adolescents in the control group increased (treatment by time interaction: $p<0.01$; fig. 1 ). The estimated effect size was -0.56 after 3 years. Thus, the magnitude of the difference between the treatment and control group after 3 years was moderate. Perceived athletic competence in the treat- 
ment group decreased over time, while that of the adolescents in the control group increased (treatment by time interaction: $\mathrm{p}<0.05$; effect size after 3 years $=-0.58$; fig. 1). The increase in self-appraisal of physical appearance over the 3 years was statistically significant for both treatment and control groups (time effect: $\mathrm{p}<0.05$ ).

Trait anxiety decreased with increasing time for adolescents in the control group, but remained at approximately the same level for adolescents in the treatment group (treatment by time interaction: $\mathrm{p}<0.05$; estimated effect size $=0.75$ after 3 years; fig. 1). Besides the three significant treatment by time interactions and the two additional significant differences over time for both groups, no additional effects were significant (table 4).

Scores of the adolescents in both groups, although on average different, showed a considerable overlap (fig. 1). The very high scores (greater than 2 SDS from the mean for age and sex) after 2 and 3 years on trait anxiety and the low score (less than 2 SDS) after 3 years on athletic competence derived from one male participant with ISS in the treatment group who had a height SDS of less than -2.5 at baseline and relatively low expectations of future height at the end of the treatment (25th percentile) compared to the start of treatment (75th percentile). The other elevated score on trait anxiety, and four low scores on athletic competence, were from different individuals, with no other extreme scores.

\section{Post-Hoc Analyses}

We inspected the common means and standard deviations of all variables that were analyzed in multilevel analyses. This assessment confirmed the conclusions of multilevel analysis. Examination of the results of the adolescents who participated at all four measurements also confirmed the results of multilevel analysis: for scholastic competence, athletic competence, and trait anxiety, the adolescents of the treatment group showed a worsening course during the 3 years of the study as compared to the adolescents of the control group (the table containing these data is not shown but may be requested from the corresponding author).

\section{Discussion}

During a combined GH and GnRHa treatment in early pubertal adolescents with ISS or SGA the adolescents in the treatment group experienced a worse psychosocial outcome than adolescents in the control group on 3 of 16 self-report variables. In contrast, parents did not observe improvement or deterioration in the psychosocial functioning of their children. The adolescents in the control group perceived improved competence of scholastic and athletic ability, and trait anxiety, while adolescents receiving the combined treatment did not. These effects were of moderate magnitude. An intervention effect on 3 of 16 variables surpasses expectations based on statistical chance. Nevertheless, since the treatment group did not differ from the control group on $81 \%$ of the comparisons, we interpret and discuss these results with caution.

Generally, studies of GH treatment (without GnRHa) in children with ISS did not demonstrate adverse effects on psychosocial functioning [29, 32, 44-47], except one which showed a somewhat worse outcome based on children's self-reports [48]. Our study, which also included a puberty-delaying hormone, showed a worse course of the perceived competence of scholastic ability for the treatment than for control group. An earlier study reported that late maturation in boys was related to low school achievement [49]. Athletic competence also showed a worse course for the adolescents that were treated with GH and GnRHa. This might be caused by the pubertal delay, which is associated with delay of muscle maturation, particularly in boys.

Trait anxiety in the treated adolescents, on average, did not change while the control group showed an improvement. One hypothesis is that this characteristic remained relatively high in the treatment group as a consequence of the daily injections and regular visits to the physician, coupled with feelings of being a patient and different. Alternatively, a different timing of physical puberty relative to peers, which is often associated with feelings of being different, may be a risk factor for trait anxiety [20-23]. While trait anxiety showed a difference between the two groups, the related constructs state anxiety, depressive mood, and inadequacy did not. Given the small sample size of our study, our findings only warn of a possible short-term adverse effect of the treatment. Our findings need replication before it is concluded that the combination of GH and GnRHa lowers perceived competence of scholastic and athletic abilities and enhances anxiety.

Time effects were found on two outcome variables. The adolescents' perception of current height and appraisal of physical appearance increased in both treated and untreated adolescents. This suggests that over time these adolescents increasingly accept being short. Generally, as individuals progress from early adolescence (1114 years) to late adolescence (15-17 years), some themes such as wanting to be typical with respect to physical ap- 
pearance and to be liked and accepted by others because of physical appearance, are becoming somewhat less important [50]. Instead, self-descriptions that include more abstract and organized descriptions of one's inner self take on more salience [50, 51].

Given the results based on adolescents' reports, it is surprising that none of the parental evaluations showed a treatment effect or a change across the 3 years of the intervention. Before initiating the treatment, the adolescents in both the treatment and control groups reported normal psychosocial adjustment compared to the general Dutch norm group, but the parents reported that their children encountered behavioral and attention problems as well as height-related stressors such as being teased and juvenilized. Furthermore, the parents were worried about their children's future chances in finding a partner or proper job [43]. With respect to the reported behavioral and attention problems, it is to be noted that we used an overly stringent criterion and likely overestimated the actual psychosocial dysfunctioning. The normative comparison group included very healthy adolescents only: any child who had been referred to a mental-health professional in the past 12 months, or who was currently receiving special educational services, was excluded from the normative sample [30, 52]. Our current analyses, as shown in table 3, suggest that the behavioral problems reported by the parents at baseline do not significantly decrease during the treatment interval. The implication that there are no short-term positive effects of the treatment on behavior is not unexpected, because the benefits of the treatment in terms of gain in height have not yet become apparent. Long-term effects have to be awaited to answer the question whether the behavioral problems will decline by hormone treatment.

Although our study is unique in investigating a combined GH and GnRHa treatment in the presence of an untreated control group, there are some limitations. We chose multilevel analysis, because this technique is suited to deal with missing values. Although our sample was relatively large as compared to other research in this area, there was limited statistical power to detect group differences. The power of our study was calculated on the basis of expected differences in height. A larger sample size would have provided the opportunity to evaluate psychosocial changes in more detail and to adjust for possible effects of demographic and diagnostic variables. Despite the small sample size, we considered the evaluation of possible developmental side effects obligatory from a clinical, developmental, and ethical point of view. The results of our study need to be interpreted together with findings from other studies. The larger power of such an analysis will allow stronger conclusions with respect to possible adverse effects of puberty-delaying hormones. The results of our study need also to be interpreted together with results of future studies in adulthood. It remains to be seen whether the possible advantages of a gain in adult height compensates for the possible disadvantages of pubertal delay.

For ethical reasons we chose to not administer placebo injections to the control group. The one study that used a placebo-controlled design ended the long-term placebo injections prematurely [32]. In our study, the results are probably not due to a placebo effect, because this would result in a better instead of worse outcome of the treatment group as compared to the control group.

In conclusion, our study indicates that a combined $\mathrm{GH}$ and GnRHa treatment may be accompanied by some adverse psychosocial consequences for adolescents with ISS or SGA, but only from the adolescents' perspective. It is therefore useful to monitor and investigate the consequences of this intervention. It is uncertain whether the hypothesized positive effects of the expected gain in final height by adulthood can sufficiently counterbalance possible short-term negative effects.

\section{Acknowledgements}

Thanks are due to Prof. Dr. H.A. Delemarre-van de Waal, Dr. J.J.J. Waelkens, and Dr. M. Jansen for their contribution to the clinical part of the study. 


\section{References}

1 Ranke MB: Towards a consensus on the definition of idiopathic short stature. Horm Res 1996;45(suppl 2):64-66.

2 Rekers-Mombarg LT, Massa GG, Wit JM, Matranga AM, Buckler JM, Butenandt O, Chaussain JL, Frisch H, Leiberman E, Yturriaga R, Aarskog D, Chatelain PG, Colle M, DacouVoutetakis C, Delemarre-van de Waal HA, Gi$\operatorname{rard} \mathrm{F}$, Gosen JJ, Irle U, Jansen M, Jean R, Job JC, Kaar ML, Kollemann F, Lenko HL, Waelkens JJ, et al: Growth hormone therapy with three dosage regimens in children with idiopathic short stature. European Study Group Participating Investigators. J Pediatr 1998; 132:455-460.

3 Loche S, Cambiaso P, Setzu S, Carta D, Marini R, Borrelli P, Cappa M: Final height after growth hormone therapy in non-growth-hormone-deficient children with short stature. J Pediatr 1994;125:196-200.

4 Wit JM, Kamp GA, Rikken B: Spontaneous growth and response to growth hormone treatment in children with growth hormone deficiency and idiopathic short stature. Pediatr Res 1996;39:295-302.

5 Buchlis JG, Irizarry L, Crotzer BC, Shine BJ, Allen L, MacGillivray MH: Comparison of final heights of growth hormone-treated vs. untreated children with idiopathic growth failure. J Clin Endocrinol Metab 1998;83:1075-1079.

6 Hintz RL, Attie KM, Baptista J, Roche A: Effect of growth hormone treatment on adult height of children with idiopathic short stature: Genentech Collaborative Group. N Engl J Med 1999;340:502-507.

7 Wit JM, Rekers-Mombarg LT: Final height gain by $\mathrm{GH}$ therapy in children with idiopathic short stature is dose dependent. J Clin Endocrinol Metab 2002;87:604-611.

8 Chatelain P: Children born with intra-uterine growth retardation (IUGR) or small for gestational age (SGA): long term growth and metabolic consequences. Endocr Regul 2000;34: 33-36.

9 Van Pareren Y, Mulder P, Houdijk M, Jansen M, Reeser M, Hokken-Koelega A: Adult height after long-term, continuous growth hormone $(\mathrm{GH})$ treatment in short children born small for gestational age: results of a randomized, double-blind, dose-response GH trial. J Clin Endocrinol Metab 2003;88:3584-3590.

10 Kamp GA, Waelkens JJ, de Muinck KeizerSchrama SM, Delemarre-Van de Waal HA, Verhoeven-Wind L, Zwinderman AH, Wit JM: High dose growth hormone treatment induces acceleration of skeletal maturation and an earlier onset of puberty in children with idiopathic short stature. Arch Dis Child 2002;87: 215-220.

11 Balducci R, Toscano V, Mangiantini A, Municchi G, Vaccaro F, Picone S, Di Rito A, Boscherini B: Adult height in short normal adolescent girls treated with gonadotropin-releasing hormone analog and growth hormone. J Clin Endocrinol Metab 1995;80:3596-3600.
12 Job JC, Toublanc JE, Landier F: Growth of short normal children in puberty treated for 3 years with growth hormone alone or in association with gonadotropin-releasing hormone agonist. Horm Res 1994;41:177-184.

13 Lanes R, Gunczler P: Final height after combined growth hormone and gonadotrophin-releasing hormone analogue therapy in short healthy children entering into normally timed puberty. Clin Endocrinol (Oxf) 1998;49:197_ 202.

14 Tanaka T, Satoh M, Yasunaga T, Horikawa R, Tanae A, Hibi I: GH and GnRH analog treatment in children who enter puberty at short stature. J Pediatr Endocrinol Metab 1997;10: 623-628.

15 Pasquino AM, Pucarelli I, Roggini M, Segni M: Adult height in short normal girls treated with gonadotropin-releasing hormone analogs and growth hormone. J Clin Endocrinol Metab 2000;85:619-622.

16 Saggese G, Cesaretti G, Barsanti S, Rossi A: Combination treatment with growth hormone and gonadotropin-releasing hormone analogs in short normal girls. J Pediatr 1995;126:468473.

17 Mul D, Oostdijk W, Waelkens JJ, Schulpen TW, Drop SL: Gonadotrophin releasing hormone agonist treatment with or without recombinant human $\mathrm{GH}$ in adopted children with early puberty. Clin Endocrinol (Oxf) 2001;55:121-129.

18 Kamp GA, Mul D, Waelkens JJ, Jansen M, Delemarre-van de Waal HA, Verhoeven-Wind L, Frolich M, Oostdijk W, Wit JM: A randomized controlled trial of three years growth hormone and gonadotropin-releasing hormone agonist treatment in children with idiopathic short stature and intrauterine growth retardation. J Clin Endocrinol Metab 2001;86:29692975.

19 Kaplowitz PB: Editorial: If Gonadotropin-releasing hormone plus growth hormone $(\mathrm{GH})$ really improves growth outcomes in short nonGH-deficient children, then what? J Clin Endocrinol Metab 2001;86:2965-2968.

20 Brooks-Gunn J: Antecedents and consequences of variations in girls maturational timing. J Adolesc Health Care 1988;9:365-373.

21 Alsaker FD: Annotation: The impact of puberty. J Child Psychol Psychiatry Allied Discip 2003;37:249-258.

22 Graber JA, Lewinsohn PM, Seeley JR, BrooksGunn J: Is psychopathology related to timing of pubertal development? J Am Acad Child Adolesc Psychiatry 1997;36:168-176.

23 Ge X, Conger RD, Elder GHj: The relationship between pubertal transition and psychological distress among adolescent boys. J Res Adolesc 2001;11:49-70.

24 Mul D, Versluis-den Bieman HJ, Slijper FM, Oostdijk W, Waelkens JJ, Drop SL: Psychological assessments before and after treatment of early puberty in adopted children. Acta Paediatr 2001;90:965-971.
25 Lundgren EM, Cnattingius S, Jonsson B, Tuvemo T: Intellectual and psychological performance in males born small for gestational age. Horm Res 2003;59(suppl 1):139-141.

26 van Pareren YK, Duivenvoorden HJ, Slijper FS, Koot HM, Hokken-Koelega AC: Intelligence and psychosocial functioning during long-term growth hormone therapy in children born small for gestational age. J Clin Endocrinol Metab 2004;89:5295-5302.

27 van der Reijden-Lakeman I, Slijper FM, van Dongen-Melman JE, de Waal WJ, Verhulst FC: Self-concept before and after two years of growth hormone treatment in intrauterine growth-retarded children. Horm Res 1996;46: 88-94.

28 Lundgren M, Cnattingius S, Jonsson B, Tuvemo $\mathrm{T}$ : Intellectual performance in young adult males born small for gestational age. Growth Horm IGF Res 2004; 14(suppl A):S7S8.

29 Huisman J: Medisch-psychologische bijdragen aan nieuwe behandelingswijzen in de kindergeneeskunde (The contribution of behavioral medicine to interventions in pediatrics); $\mathrm{PhD}$ thesis, Free University, Amsterdam, 1993.

30 Verhulst FC, Van der Ende J, Koot HM: Handleiding voor de CBCL 4-18 (Manual for the Child Behavior Check List). Assen/Maastricht, Van Gorcum, 1996.

31 Grew RS, Stabler B, Williams RW, Underwood LE: Facilitating patient understanding in the treatment of growth delay. Clin Pediatr (Phila) 1983;22:685-690.

32 Ross JL, Sandberg DE, Rose SR, Leschek EW, Baron J, Chipman JJ, Cassorla FG, Quigley CA, Crowe BJ, Roberts K, Cutler GB Jr: Psychological adaptation in children with idiopathic short stature treated with growth hormone or placebo. J Clin Endocrinol Metab 2004;89:4873-4878.

33 Veerman JW, Straathof MAE, Treffers PDA, van den Bergh BRH, ten Brink LT: Handleiding bij de Competentie Belevingsschaal voor Kinderen, CBSK (Manual of the Self Perception Profile for Children - Dutch version). Amsterdam, Lisse, Swets \& Zeitlinger, 1997.

34 Treffers PDA, Goedhart AW, Veerman JW, Van den Bergh BRH, Ackaert L, Rycke L: Competentiebelevingsschaal voor adolescenten (CBSA), handleiding (Manual of the Self perception Profile for Adolescents - Dutch version). Amsterdam, Lisse, Swets \& Zeitlinger, 2002.

35 Bakker FC, Van Wieringen PCW, Van der Ploeg HM, Spielberger CD: Handleiding bij de Zelf-Beoordelings-Vragenlijst voor kinderen, ZBV-K (Manual of the Stait-Trait Anxiety for children - Dutch version). Amsterdam, Lisse, Swets \& Zeitlinger, 1989.

36 de Wit CAM: Handleiding bij de depressievragenlijst voor kinderen, DVK en KDVK (Manual of the short depression questionnaire for children - Dutch version). Amersfoort/Leuven, Acco, 2001. 
37 Luteijn F, van Dijk H, van der Ploeg FAE: Handleiding bij de Junior Nederlandse Persoonlijkheidsvragenlijst, NPV-J (Manual of the Dutch Personality Questionnaire - junior). Lisse, Swets \& Zeitlinger, 1989.

38 Maas CJM, Snijders TAB: The multilevel approach to repeated measures with missing data. Using multilevel software to obtain estimates and tests for the Manova model with possible incomplete data. Qual Quant 2002; 37:71-89.

39 Hedeker D, Gibbons RD: MIXREG: a computer program for mixed-effects regression analysis with autocorrelated errors. Comput Meth Programs Biomed 1996;49:229-252.

40 Hedeker D, Gibbons RD: MIXOR: a computer program for mixed-effects ordinal regression analysis. Comput Meth Programs Biomed 1996;49:157-176.

41 Hedeker D: MIXNO: a computer program for mixed-effects nominal logistic regression. $\mathrm{J}$ Stat Software 1999;4:1-92.

42 Cohen J: A power primer. Psychol Bull 1992; 112:155-159.
43 Visser-van Balen H, Geenen R, Kamp GA, Huisman J, Wit JM, Sinnema G: Motives for choosing growth-enhancing hormone treatment in adolescents with idiopathic short stature: a questionnaire and structured interview study. BMC Pediatr 2005;5:15.

44 Stabler B, Frank NC: Quality of life and the psychiatric status of individuals treated with growth hormone in childhood; in Drotar D (ed): Measuring Health-Related Quality of Life in Children and Adolescents: Implications for Research and Practice. Mahwah, Lawrence Erlbaum Associates, 1998, pp 273-286.

45 Downie AB, Mulligan J, McCaughey ES, Stratford RJ, Betts PR, Voss LD: Psychological response to growth hormone treatment in short normal children. Arch Dis Child 1996;75:3235 .

46 Rekers-Mombarg LT, Busschbach JJ, Massa GG, Dicke J, Wit JM: Quality of life of young adults with idiopathic short stature: effect of growth hormone treatment. Dutch Growth Hormone Working Group. Acta Paediatr 1998;87:865-870.
47 Boulton TJ, Dunn SM, Quigley CA, Taylor JJ, Thompson L: Perceptions of self and short stature: effects of two years of growth hormone treatment. Acta Paediatr Scand Suppl 1991; 377:20-28.

48 Theunissen NC, Kamp GA, Koopman HM, Zwinderman KA, Vogels T, Wit JM: Quality of life and self-esteem in children treated for idiopathic short stature. J Pediatr 2002;140: 507-515.

49 Dubas JS, Graber JA, Peterson AC: The effects of pubertal development on achievement during adolescence. Am J Educ 1991;99:444460.

50 Kroger J: Identity development: adolescence through adulthood. Thousand Oaks, Sage, 2000.

51 Harter S: The Construction of the Self: A Developmental Perspective. New York, The Guilford Press, 1999.

52 Sandberg DE, Meyer-Bahlburg HF, Yager TJ: The Child Behavior Checklist nonclinical standardization samples: should they be utilized as norms? J Am Acad Child Adolesc Psychiatry 1991;30:124-134. 